\title{
EFFECT OF THERMAL BARRIER COATING FOR THE IMPROVEMENT OF SI ENGINE PERFORMANCE \& EMISSION CHARACTERISTICS
}

\author{
J.Rajasekaran ${ }^{1}$, B.M.Gnanasekaran ${ }^{2}$, T.Senthilkumar ${ }^{3}$, B.Kumaragurubaran ${ }^{4}$, M.Chandrasekar $^{5}$ \\ ${ }^{1,2,3,4,5}$ Department of Mechanical engineering, University College of engineering, Anna University, \\ BIT Campus, Trichy-620 024, Tamilnadu, India.
}

\begin{abstract}
As per the second law of thermodynamics the efficiency of the engine depends upon the extraction of work against the heat supplied. Minimisation of heat rejection leads to increase the work. Heat rejection takes place through the engine piston, valves and cylinder heads to the surroundings. The aim of the study is to minimise this heat rejection to the surroundings. Heat transfer through the engine parts is minimised by applying the thermal barrier coating materials on the top surface of the engine piston, cylinder heads and valves. In this study an attempt is made to reduce the intensity of thermal and structural stresses by using a layer of the ceramic material, like Yttria stabilized zirconia (YSZ) which has low thermal conductivity, high thermal resistance, chemical inertness, high resistance to erosion, corrosion and high strength was selected as a coating material for engine component. This study present the effect of coating on the piston and the performance of modified four stroke petrol engine and the emission characteristics of the exhaust gas.
\end{abstract}

Key words: Yttrium - zirconium coating, Low heat rejection, Thermal barrier coatings, Engine performance and Emission characteristics

\section{INTRODUCTION}

Energy conservation and efficiency have always been the quest of engineers concerned with internal combustion engines. Even the petrol engine rejects about two thirds of the heat energy of the fuel, one-third to the coolant, and one third to the exhaust, leaving only about one-third as useful power output. Theoretically if the heat rejected could be reduced, then the thermal efficiency would be improved. Low Heat Rejection engines aim to do this, by reducing the heat lost to the coolant.

Thermal Barrier Coatings (TBCs) in petrol engines lead to advantages including higher power density, fuel efficiency, and multi fuel capacity due to higher combustion chamber temperature. Using TBC can increase engine power and decrease the specific fuel consumption and increase the exhaust gas temperature. Although several systems have been used as TBC for different purposes, yttria stabilized zirconia has received the most attention. Several important factors playing important roles in TBC lifetimes including thermal conductivity, thermal, chemical stability at the service temperature, high thermo mechanical stability to the maximum service temperature and the thermal expansion coefficient (TEC) [4]

The petrol engine with its combustion chamber walls insulated by ceramics is referred to as Low Heat-Rejection (LHR) engine [7]. The LHR engine has been conceived basically to improve fuel economy by eliminating the conventional cooling system and converting part of the increased exhaust energy into shaft work using the turbocharged system.

This study presents effect of Zirconia coating on the piston, cylinder head and valves on the performance of the modified four stroke petrol engine and emission characteristics of the exhaust gas.

\section{THERMAL BARRIER COATING:}

Thermal barrier coatings (TBCs) have been successfully applied to the internal combustion engine, in particular the combustion chamber, to simulate adiabatic engines. The objectives are not only for reduced in-cylinder heat rejection and thermal fatigue protection of underlying metallic surfaces, but also for possible reduction of engine emissions. The application of $\mathrm{TBC}$ reduces the heat loss to the engine coolingjacket through the surfaces exposed to the heat transfer such as cylinder head, liner, piston crown and piston rings. The insulation of the combustion chamber with ceramic coating affects the combustion process and hence the performance and exhaust emissions characteristics of the engines [2].

A typical TBC system consists of (i) the top coat (TC), a porous ceramic layer that acts as the insulator, (ii) the bond coat $(\mathrm{BC})$, an oxidation-resistant metallic layer between the 
substrate and the TC and (iii) the super alloy or other material substrate that carries the structural load [6].

\section{THE TOP COAT:}

The top coat provides thermal insulation for the underlying substrate. The specifications for this coating require a material that combines low thermal conductivity and a coefficient of thermal expansion (CTE) that it is as similar as possible to that of the substrate, so that generation of stresses during thermal cycling can be minimized. The preferred material for this application is zirconia. Zirconia may exist as three solid phases, which are stable at different temperatures. At temperatures up to $1200^{\circ} \mathrm{C}$, the monoclinic phase $(\mathrm{m})$ is stable. Zirconia transforms from the monoclinic to the tetragonal phase (t) above $1200^{\circ} \mathrm{C}$ and above $2370^{\circ} \mathrm{C}$ to the cubic phase (c). Transformation from $\mathrm{m}$ to the $\mathrm{t}$ phase has an associated volume decrease of $4 \%$. To prevent catastrophic cracking as a result of the volume changes accompanying the $t \rightarrow m$ transformation, which occurs at temperatures within the range of the working environment in gas turbines, stabilizers are added to the zirconia. These stabilize zirconia into its cubic or tetragonal phases. Early attempts used $\mathrm{MgO}$ to stabilize zirconia in its cubic state, by adding $25 \mathrm{wt} \% \mathrm{MgO}$.

However, during heat treatment the zirconia reverts to its monoclinic form and the stabilizing oxide precipitates out from solid solution, affecting the thermal conductivity. Zirconia can be fully stabilised to its cubic phase by adding $20 \%$ yttria by weight. However, such fully stabilised zirconia coatings perform very poorly in thermal cycling tests . Typically $7-9 \mathrm{wt} \%$ yttria is used to partially stabilise zirconia, although other stabilizers have been used as well. Other stabilizers include $\mathrm{CaO}, \mathrm{MgO}, \mathrm{CeO} 2 \mathrm{Sc} 2 \mathrm{O} 3$. The basic criteria for the selection of a suitable stabiliser include a suitable cation radius, similar to that of zirconium, and a cubic crystal structure. Inspite of the addition of a stabilizer in order to ensure phase stability of the top coat, phase changes in the top coat might still be induced during service.

An important aspect of the performance of top coat material is its sintering behaviour. After prolonged heating during service, sintering of the top coat can occur. This will result in healing of the micro cracks and pores that will in turn reduce the strain tolerance of the coating and increase the likelihood for spallation.

\section{BOND COAT:}

The bond coat protects the underlying substrate from oxidation and improves adhesion between the ceramic and the metal. Oxidation occurs due to oxygen reaching the bond coat by diffusion through the lattice of the top coat and permeation through the pores. The yield and creep characteristics of the bond coat are thought to be significant for the performance of the TBC system.
Commonly used bond coats can be divided in two categories: MCrAlY (where $\mathrm{M}=\mathrm{Co}$ or $\mathrm{Ni}$ or both) and Pt-modified aluminides. These coatings were developed for use as protective coatings against oxidation and hot corrosion. When exposed to an oxidizing environment, they form a stable dense alumina layer in preference to other oxides. This alumina, often termed the thermally grown oxide (TGO) prevents further attack of the underlying material, due to its low oxygen diffusivity and its good adherence. MCrAlY bond coats are usually deposited by low -pressure plasma spraying and consist of two phases ( $\beta$-NiAl and either $\gamma$-Ni solid solution or $\gamma^{\prime} \mathrm{Ni3Al}$ ). Small amounts of $\mathrm{Y}$ are added in order to improve TGO adherence .Yttrium additions have been found to inhibit void formation at the TGO/BC interface. In addition, Y-rich oxide protrusions are formed in the oxide that mechanically pegs the oxide to the alloy. Furthermore, yttrium has the effect of decreasing the grain size of the TGO and thus raising its mechanical strength.

Pt-modified aluminides are usually fabricated by electroplating a thin $\mathrm{Pt}$ layer on the superalloy and then aluminizing by chemical vapor deposition or pack cementation. These coatings usually consist of a singlephase- $\beta$ with $\mathrm{Pt}$ in solid solution. Platinum additions improve the spallation resistance of conventional aluminide coatings. However, the mechanisms by which this occurs are not fully understood.

Optimum adhesion between the bond coat and the top coat is attained differently in plasma sprayed and EB-PVD coatings. In plasma sprayed coatings, it is achieved by mechanical interlocking of the two interfaces, so the surface roughness of the bond coat is an important parameter. In contrast, EB-PVD coatings achieve maximum durability when applied to a smooth (preferably polished) surface, free of absorbed gases or loose oxides. Asperities in the BC/TGO interface are thought to serve as nucleation sites for cracks that cause coating spallation when they coalesce.

MCrAlY bond coats creep at temperatures above $800^{\circ} \mathrm{C}$. At this temperature, stresses in the $\mathrm{BC}$ are relieved and it is nonload bearing. The creep behaviour of the $\mathrm{BC}$ can have a significant influence on the stress state of the TBC and thus on the failure mechanisms [8].

\section{NICKEL BASED SUPERALLOYS:}

Superalloys have been described as "alloys developed for elevated temperature service, usually based on group VIIIA elements, where relatively severe mechanical stressing is encountered and where high surface stability is frequently required". Progressively higher amounts of Aluminium, Titanium and associated compositional modifications increased the temperature capability of the alloys. Nickel based superalloys can currently operate up to homologous temperatures of $1100^{\circ} \mathrm{C}$. 
Nickel provides a face-centered cubic(FCC) lattice, which has a high modulus, 5 independent slip systems and low diffusivity for substitutional solutes. The formation of coherent gamma prime precipitates and carbides lead to strengthening. Advanced piston materials have a relatively high volume fraction of gamma prime (Ni3Al), around $70 \%$. Aluminium forms a stable alumina scale during exposure to high temperature and also strengthens the alloy by forming gamma prime[6].

Superalloys were conventionally produced by casting methods. However, superalloys produced by casting methods often did not exhibit consistent creep properties. This problem led to the development of directional solidification (DS), which produces castings with grains aligned in the direction of maximum stress and few grain boundaries normal to this direction. Directional solidification is achieved by ensuring that the heat during solidification of the casting is removed in a direction parallel to the desired growth direction, while a liquid/solid interface perpendicular to the solidification direction is maintained. DS resulted in a significant increase in the creep strength of these superalloys, relative to conventionally cast alloys, and led to an increase in the temperature capabilities of superalloys [8].

A further important development in the processing of superalloys was the production of single crystal castings. This technology was achieved by extending the DS technology and adding a simple modification to the casting mould, either a crystal selection device or a "seed" crystal. Single crystals have improved creep properties relative to DS superalloys.

\section{COATING SYSTEM:}

\section{Plasma Sprayed Coatings:}

A characteristic of all thermal spray processes is a highly concentrated power source, to which the coating material is fed in the form of powder, wire or rod. The coating material is melted and accelerated to the substrate, forming the coating. The coating is formed of many overlapping splats, solidifying one after another and locking one to another. Due to the high kinetic energy of the droplets, the splats spread over the substrate, forming a pancake. It is widely used for the production of TBCs.

PS-TBCs have the necessary strain tolerance required for most of the applications in which such coatings are currently applied. This is largely a consequence of the presence of many fine micro cracks and pores in the microstructure, which results in low stiffness. This low stiffness prevents large stresses from being generated in the top coat. The thermal conductivity of plasma sprayed coatings range from 0.5-1.4 $\mathrm{W} / \mathrm{mK}$, which is lower than corresponding values for EB-PVD coatings The microstructure of PS TBCs exhibits pores and grain boundaries aligned perpendicular to the direction of heat flux. Grain boundaries and pores hinder heat transfer. The shape and orientation of porosity with respect to the heat flux are more critical factors than the total amount of porosity for the thermal conductivity of PS coating. EB-PVD coatings offer benefits over PS coatings in terms of the erosion resistance. In PS coatings, the erosion occurs in the form of removal of the mechanically bonded splats by the erosive material. Since intersplat porosity is already present, the energy required for this process is low.

The low cost associated with the PS process compared to EBPVD makes PS TBCs is the more attractive. However, applications that require excellent strain tolerance, good surface finish and erosion resistance, such as in aerofoils and aero-gas turbines, EB-PVD coatings will be favoured.

\section{THE PLASMA SPRAYING PROCESS:}

\section{The Plasma Jet:}

Plasma Spraying, first conducted by Reinecke in 1939, was advanced in the late 50's by several other scientists. Since then, it has become increasingly sophisticated and is nowadays widely used in surface technology.

The plasma spraying gun consists principally of two electrodes.

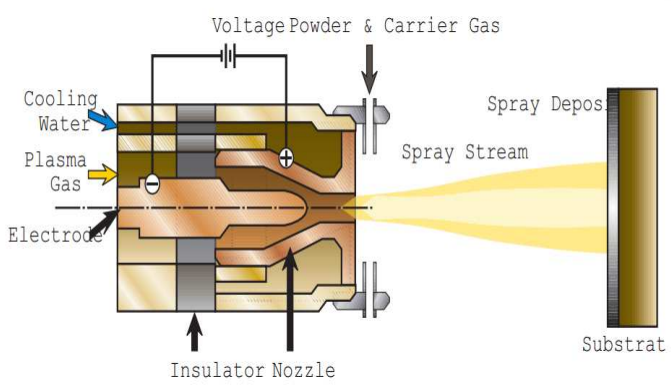

\section{Schematic diagram of Plasma spray gun}

Figure shows a schematic of the plasma spray gun, with the thoriated tungsten cathode inside the water-cooled copper anode. A gas, commonly a mixture of argon and hydrogen, is injected into the annular space between the two. To start the process, a DC electric arc is stuck between the two electrodes. The electric arc produces gas ionisation, i.e. gas atoms lose electrons and become positive ions. Electrons move with high velocity to the anode, while ions move to the cathode. On their way, electrons and atoms collide with neutral gas atoms and molecules. Hence, the electric arc continuously converts the gas into a plasma (a mixture of ions and electron of high energy). The plasma is on average, electrically neutral and characterized by a very high temperature. The kinetic energy of the plasma (mostly carried by free electrons) is converted 
into thermal energy during collisions between ions, electrons and atoms. In this way, the plasma is capable of producing temperatures up to approximately $104 \mathrm{~K}$. The hot gas exits the nozzle of the gun with high velocity.

Powder material is fed into the plasma plume. The powder particles are melted and propelled by the hot gas onto the surface of the substrate. When individual molten particles hit the substrate surface, they form splats by spreading, cooling and solidifying. These splats then incrementally build the coating.

Plasma plumes exhibit radial temperature gradients. Whereas particles that pass through the central core of the plasma tend to be melted, superheated or even vaporised, particles that flow near the periphery may not melt at all. This will affect the final structure of the coating, which may contain partially molten or unmelted particles. Voids, oxidised particles and unmelted particles can appear in the coating. These effects may be desirable, or they may be unwanted, depending on the requirements of the coating.

\section{Coatings Microstructure and Properties:}

Plasma sprayed coatings are built up particle by particle. Molten droplets arrive one at a time and impact with the underlying material, which consist of previously solidified droplets (splats), and there they solidify. Hence, the microstructure of the PS coatings is different from that of most other materials. Plasma sprayed coatings have a nonhomogeneous, layered structure, consisting of splats with a pancake-like shape. Also, partially molten particles, oxides and voids are present in a typical PS structure [1].

Porosity levels in plasma sprayed ceramic coatings are generally in the range $3-20 \%$. Porosity might be in the form of inter splat porosity (fine gaps between one lamella and another) or larger irregularly shaped void which result from incomplete conformation of splats to the topography of the impact site. For thermal barrier coatings, high porosity may be desirable, since the thermal conductivity of the coating is decreased by the presence of porosity.

Plasma sprayed coatings also have different mechanical properties from corresponding bulk material. Strength values of the coatings are usually only a small fraction of the values of corresponding dense materials. The Young's modulus of metallic coatings obtained by plasma spraying has been found to be of the order of $1 / 3$ that of bulk material, though ceramic coatings gives lower modulus. For PSZ, typical values of Young's modulus for as-sprayed coatings are 10-40 GPa in comparison to $210 \mathrm{GPa}$ for dense zirconia. The thermal conductivity of PS coatings is usually lower than corresponding values for the bulk material. The coatings exhibit pores and planar defects which inhibit heat transfer. The coefficient of thermal expansion, however, is not influenced by the coating morphology since pores and voids do not contribute to expansion.

Adhesion of plasma sprayed coatings to the underlying substrate is achieved mainly by mechanical interlocking. Therefore, the surface roughness of the substrate often plays a role in interfacial adhesion.

During plasma spraying, stresses are generated in the coating as consequence of the rapid solidification of the molten droplets (quenching stresses) and during subsequent cooling as a result of mismatch of the thermal expansion coefficients of substrate and coating.

\section{Advantages of Plasma Spray Coating:}

It can deposit metals, ceramics or combinations of these, since the high plasma temperatures permit the spraying of materials with high melting points. High particle velocities result in generating microstructures with relatively low porosity and high bond strength. It is a Economical process because it is conducted in atmospheric condition. When compared with EB-PVD coating, the thermal conductivity of plasma sprayed coating ranges is low.

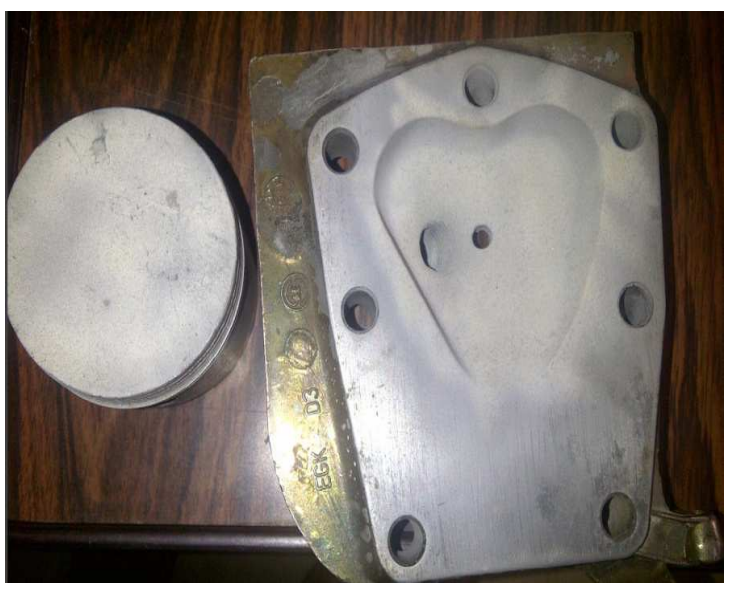

Fig.1Engine parts after coating

\section{EXPERIMENTAL SETUP:}

A Honda GK 200 engine was tested with brake drum load. Table 1 tabulates the specification of the engine. The engine tests were conducted in single cylinder, air cooled spark ignition engine at constant speed of $2500 \mathrm{rpm}$. Two types of test were conducted namely base line test and coated piston test by the following procedure. The load was given as $20 \%$, $40 \%, 60 \%$, and $80 \%$ and full load and the readings were taken. For each load the time taken for 10CC of fuel was measured. The exhaust emission and smoke parameter was measured by exhaust gas analyzer and smoke meter. Initially readings were taken normal (uncoated) piston. After taking the readings, the 
engine parts were dismantled. Cylinder heads, piston, walls were coated with YSZ. The coated parts of the engines are shown in the fig.1. Same procedure was repeated to predict the performance of the engine with the coating. Fig. 2 shows the schematic diagram of the experimental setup.

\section{TABLE I}

Specification of the engine

Make
Type

\section{Honda GK 200}

single cylinder, 4 stroke, air cooled, horizontal shaft.

Displacement 197CC

Bore $\times$ stroke

$67 \mathrm{~mm} \times 56 \mathrm{~mm}$

Compression ratio $4.5: 1$

Fuel petrol

Rated brake power $2.28 \mathrm{KW}$ at $3600 \mathrm{rpm}$.

Max.torque $\quad 0.8 \mathrm{~kg}-\mathrm{m} / 2500 \mathrm{rpm}$

Ignition system fly wheel magneto

Ignition timing $20^{\circ} \mathrm{BTDC}$ (fixed)

Air cleaner oil bath type

Dry weight $18 \mathrm{~kg}$

Dimensions $\quad 338 \mathrm{~mm} \times 404 \mathrm{~mm} \times 423 \mathrm{~mm}$

Starting recoil start

Dynamometer arm length $0.195 \mathrm{~mm}$

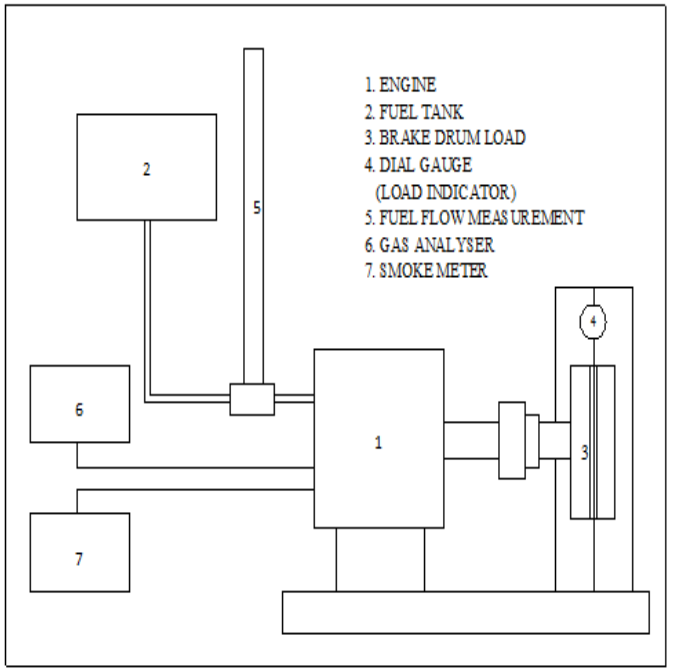

Fig.2 Schematic diagram of the experimental setup

\section{RESULTS AND DISCUSSION:}

The low heat rejection (LHR) engine concept is based on minimising this heat rejection to the coolant and recovering the energy in the form of useful work. Zirconia is a low thermal conductivity material. It will act as a barrier for the heat transfer to the surroundings from the engine's combustion chamber and reduces the heat loss from the engine. The various parameters which were affected by zirconia coated piston is discussed below:-

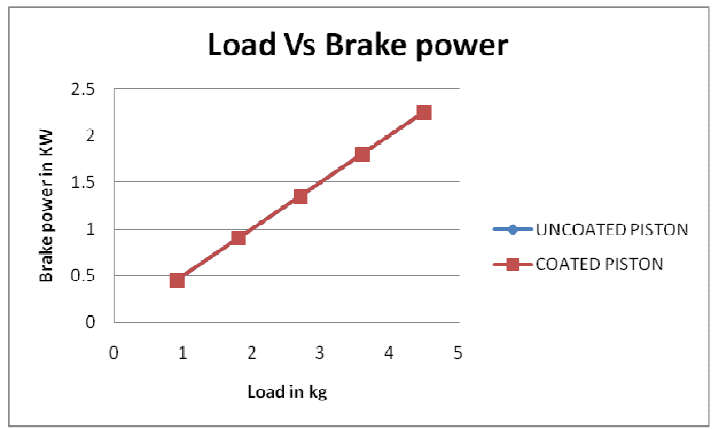

Fig.3

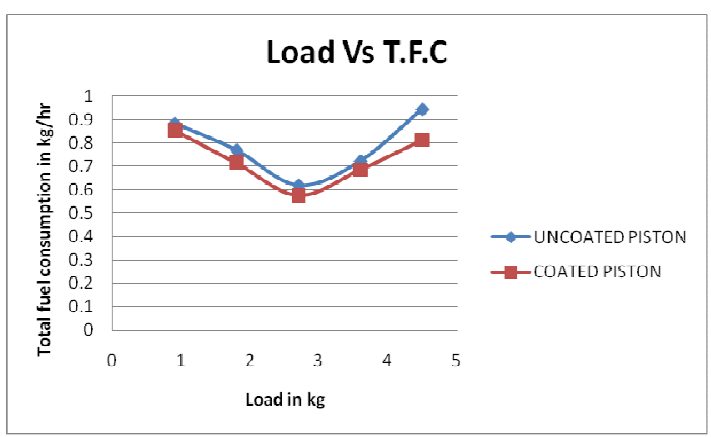

Fig.4

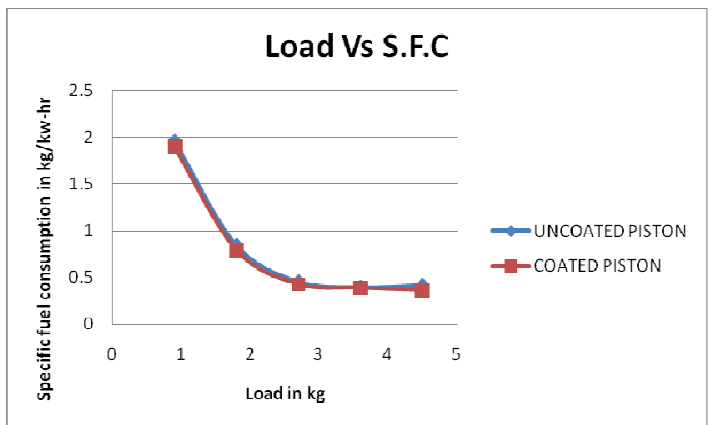

Fig.5 


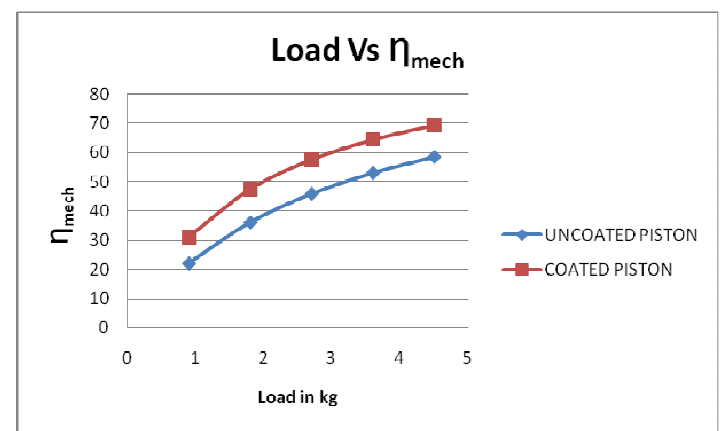

Fig.6

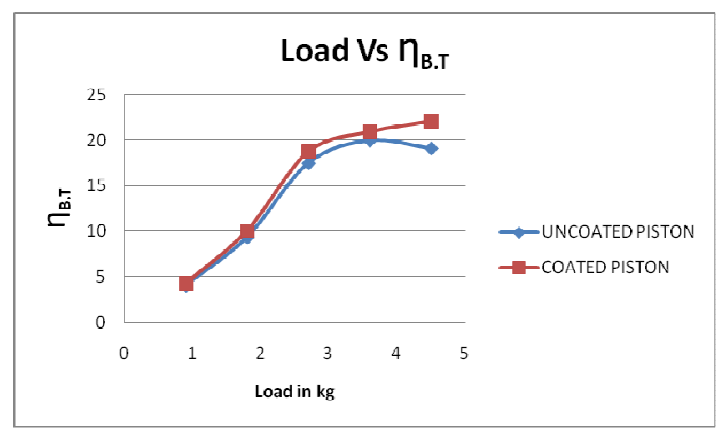

Fig.7

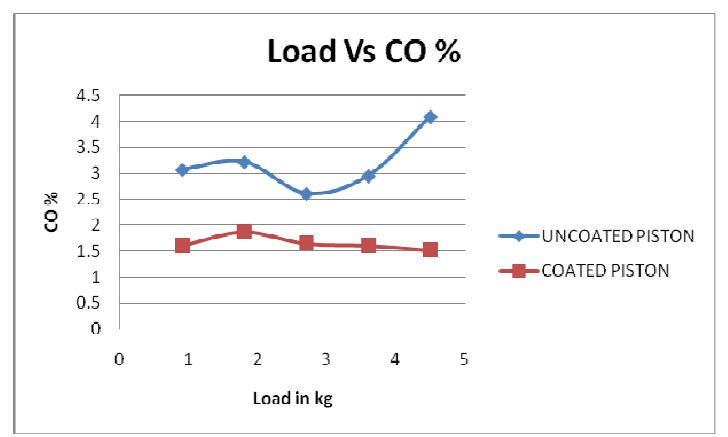

Fig.8

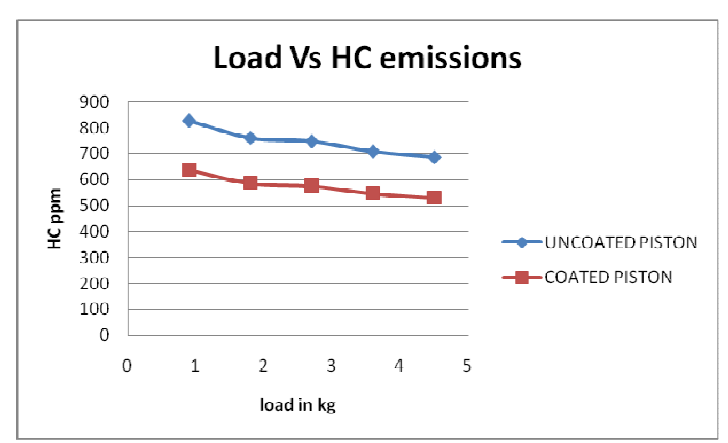

Fig.9

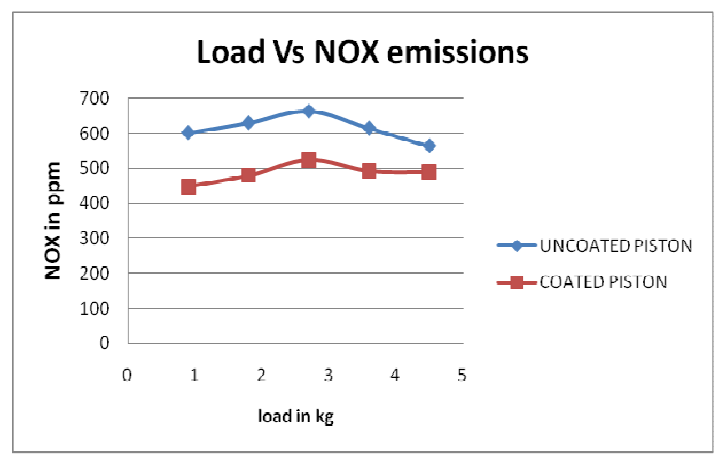

Fig.10

\section{Brake Power (B.P):}

Fig.3 shows the comparison of brake power for various loads. The parameters affected the brake power are the torque and the speed. The testing was carried out for the constant speed of $2500 \mathrm{rpm}$ for both coated and uncoated piston. The loads are taken as $20 \%, 40 \%, 60 \%, 80 \%$ and full load condition for both the case. Therefore brake power is same for both the case.

\section{Total Fuel Consumption (T.F.C):}

Fig.4 shows the variations of total fuel consumption of the standard engine and compared with coated piston. It is clear that the total fuel consumption of the engine after coating is reduced. This will increase the brake thermal efficiency of the engine. This is due to the reduction of heat loss to surroundings from the engine. From that it is obvious that there will be an excess heat in the engine, when compared with the amount of heat in the engine without coating, thereby increasing the brake thermal efficiency of the engine. Also it is observed that TFC is reduced up to some extent and it is increased for higher power requirement. It is low up to $60 \%$ of the load and then it is increases.

\section{Specific Fuel Consumption (S.F.C):}

From the fig.5, it is clear that SFC is high for low loads and it is decreasing when the load increases. Moreover same for coated and uncoated pistons, but at the higher loads a significant change in SFC occurs in coated pistons. The reduction of SFC is $0.25 \mathrm{~kg} / \mathrm{kw}-\mathrm{hr}$ at $80 \%$ loads and 0.73 $\mathrm{kg} / \mathrm{kw}-\mathrm{hr}$ at full load condition for coated piston. It is due to that the TFC increases for higher load conditions.

\section{Mechanical Efficiency:}

From the fig.6, it is observed that the mechanical efficiency is increasing for the coated piston from low load conditions to a higher load conditions. The efficiency is always $10 \%$ higher in the coated piston from low load to a higher load due to the increases of indicated power in the coated piston when compared with uncoated piston. The parameters affected the 
indicated power are brake power and friction power. Though the brake power is same for both the cases at all loads, the friction power is $0.6 \mathrm{kw}$ higher in the uncoated pistons. Therefore the mechanical efficiency is always higher in the case of coated piston.

\section{Brake Thermal Efficiency:}

Fig.7, shows that brake thermal efficiency is low for the both the cases, because of the low brake power at low loads. Then it is increases due to the brake power increases. A significant improvement is observed at the full load conditions, the brake thermal efficiency is increases above $3 \%$ in the coated piston. It is due to the TFC of coated piston is $0.131 \mathrm{~kg} / \mathrm{hr}$ less than the uncoated piston at the full load

\section{NOX Emissions:}

From the fig.10, it is clear that there is a greater reduction of oxides of Nitrogen due to coating because of nitrogen has observed by zirconia. Generally oxygen availability is high in petrol, so at high temperature nitrogen easily combines with oxygen, but availability of nitrogen is less due to coating and therefore forms less NOX. It is observed that the NOX emissions are slightly increased for with and without coating up to $60 \%$ of the load and then these emissions reduces up to full load. The difference level is $150 \mathrm{ppm}$ at low load and then it is slightly decreases when the load increases. $73 \mathrm{ppm}$ difference is observed at full load conditions for both the case of the piston.

\section{Unburned HC Emissions:}

The measured unburned $\mathrm{HC}$ emissions for uncoated and coated engine pistons are shown in fig.9. The HC emissions are reduced when the engine running with coated piston. Because at high temperature, engine will have sufficient amount of oxygen, which mixes with $\mathrm{HC}$ emissions. As a result, $\mathrm{HC}$ will split into $\mathrm{H}$ and $\mathrm{C}$, which mixes with $\mathrm{O}$ 2, thereby reducing $\mathrm{HC}$ emissions. The difference levels are approximately $180 \mathrm{ppm}$ at low load and 150ppm at full load.

\section{CO Emissions:}

Fig. 8 shows the emissions of $\mathrm{CO}$ for various loads. It is found that the $\mathrm{CO}$ is decreased after coating due to complete combustion. At high temperature $\mathrm{C}$ easily combines with $\mathrm{O} 2$ and reduces $\mathrm{CO}$ emission. At low load $\mathrm{CO}$ emissions are 1.4 $\%$ (by volume) less than the uncoated piston. This range of difference is maintained up to $60 \%$ of the load and then the $\mathrm{CO}$ emissions are increased in the uncoated piston. At full load the differences reaches $2.5 \%$.

\section{CONCLUSIONS}

As the zirconia is a low thermal conductivity material, it reduces the heat loss from the cylinder to the surroundings.
Therefore the efficiencies are increased and the emissions are reduced because of various chemical reactions takes place inside the cylinder at high temperature. Brake thermal efficiency and mechanical efficiency of coated piston are increased by the average value of $9 \%$ and $25 \%$ respectively. $7 \%$ reduction in total fuel consumption and $6 \%$ reduction in specific fuel consumption were achieved with the coated piston. $14 \%$ of NOX emissions were reduced due to coating because of nitrogen has observed by zirconia. $23 \%$ of unburned $\mathrm{HC}$ emissions were reduced by using the coated piston. CO emissions are reduced by $48 \%$ because of at high temperature $\mathrm{C}$ easily combines with $\mathrm{O} 2$ and reduces $\mathrm{CO}$ emission.

\section{REFERENCES:}

[1] Mesut Durat,Murat Kapsiz,Ergun Nart, Ferit Ficci and AdnanParlak (2011) 'The effects of coating materials in spark ignition engine design' ELSEVIER.

[2] Siew Hwa Chan(2000) 'Performance and emissions characteristics of a partially insulated gasoline engine', ELSEVIER.

[3] Idris Cesur (2011) 'The effects of modified ignition timing on cold start HC emissions and WOT performance of an LPG fuelled SI engine with thermal barrier layer coated piston' International Journal of the Physical Sciences Vol. 6(3), pp. 418-424, 4 February.

[4] Ramesh B.Poola, B Nagalingam and K.V.Gopalakrishnan "Performance of Thin-CeramicCoated Combustion Chamber with Gasoline and Methanol as Fuels in a Two-Stroke SI Engine”. SAE Technical Paper 941911, 1994.

[5] Senthilkumar Tamilkolundu and Kumaragurubaran Balasubrmanian, (2012) "Evaluation of engine performance and emission characteristics of zirconia coated piston surface in SI engine' Journal of Environmental Research And Development Vol. 7 No. $1 \mathrm{~A}$.

[6] Sofia A. Tsipas,(2005) 'Thermophysical Properties of Plasma Sprayed Thermal Barrier Coatings' thesis of University Of Cambridge, Department of Materials Science and Metallurgy.

[7] P.Lawrence ,P.Koshy Mathews and B.Deepanraj, (2011) 'Experimental investigation of zirconia coated high compression spark ignition engine with ethanol as fuel' Journal of scientific and industrial research Vol.70.

[8] Vanni Lughi, Vladimir K. Tolpygo, David R. Clarke(2004) "Microstructural aspects of the sintering of thermal barrier coatings" Materials Science and Engineering A368 (2004) 212-221.

[9] J.A. Haynes, M.K. Ferber, and W.D. Porter, "Thermal Cycling Behavior of Plasma-Sprayed Thermal Barrier Coatings with Various MCrAIX Bond Coats" Volume 9(1) March 2000 Journal of Thermal Spray Technology. 